\title{
ANALYSIS ON TYPHOON LONGWANG INTENSITY CHANGES OVER THE OCEAN VIA SATELLITE DATA
}

Chung-Chih Liu

Teaching Center of Natural Science, Minghsin University of Science and Technology, Hsin-Chu county, Taiwan, R.O.C., ccliu@must.edu.tw

Tian-Yow Shyu

Department of Geography, Chinese Culture University, Taipei, Taiwan, R.O.C.

Chun-Chieh Chao

Weather Wing of Air Force, Taipei, Taiwan, R.O.C.

Yu-Feng Lin

Weather Wing of Air Force, Taipei, Taiwan, R.O.C.

Follow this and additional works at: https://jmstt.ntou.edu.tw/journal

Part of the Oceanography and Atmospheric Sciences and Meteorology Commons

\section{Recommended Citation}

Liu, Chung-Chih; Shyu, Tian-Yow; Chao, Chun-Chieh; and Lin, Yu-Feng (2009) "ANALYSIS ON TYPHOON LONGWANG INTENSITY CHANGES OVER THE OCEAN VIA SATELLITE DATA," Journal of Marine Science and Technology. Vol. 17: Iss. 1, Article 4.

DOI: $10.51400 / 2709-6998.1973$

Available at: https://jmstt.ntou.edu.tw/journal/vol17/iss1/4

This Research Article is brought to you for free and open access by Journal of Marine Science and Technology. It has been accepted for inclusion in Journal of Marine Science and Technology by an authorized editor of Journal of Marine Science and Technology. 
ANALYSIS ON TYPHOON LONGWANG INTENSITY CHANGES OVER THE OCEAN VIA SATELLITE DATA

\section{Acknowledgements}

This research is primarily supported by The National Science Council, R.O.C. with grants

96-2625-Z-159-002 and 96-2745- M-159-001. Meanwhile, we also would like to thank the Weather Central CAFROC for providing the satellite data. 


\title{
ANALYSIS ON TYPHOON LONGWANG INTENSITY CHANGES OVER THE OCEAN VIA SATELLITE DATA
}

\author{
Chung-Chih Liu*, Tian-Yow Shyu**, Chun-Chieh Chao***, \\ and Yu-Feng Lin***
}

Key words: typhoon, anticyclonic divergence, radiate.

\begin{abstract}
The changes in the typhoon intensity are a very important process. In this study, we used satellite data to analyze the cloud structure of Typhoon Longwang. Results show that the changes in the high level cirrus pattern seemed to have a connection to the typhoon intensity. During the time period from 0600UTC to 1200UTC 30 September 2005, the high level cirrus clouds of Typhoon Longwang radiated from the inner core region. The cloud area that Typhoon Longwang covered grew larger, and the pattern changed from a asymmetric to symmetric distribution during 0000UTC to 1200UTC 30 September 2005. The best track from the Joint Typhoon Warning Center also showed that Typhoon Longwang's intensity evidently decreased, but the speed did not change as much, and the radius of $17.2 \mathrm{~m} / \mathrm{s}$ wind speeds increased during that period. According to the divergence and vorticity field of the reanalysis data from the European Center for Medium Range Weather Forecasting forecast model, it shows that the outflow and rotation of the high level clouds decreased from 0000UTC to 1200UTC 30 September, which may be a key reason in why Typhoon Longwang's intensity decreased.

A vertical structure with low level inward convergence and high level anticyclonic divergence were considered to be an important factor behind the pressure deepening, leading to the typhoon's development. However, this study shows that the high level airflow of Typhoon Longwang radiated outward, resulting in its intensity to weaken. These results demonstrate that the cloud pattern observed by satellite images still serve as a valuable approach in determining the typhoon intensity.
\end{abstract}

Paper submitted 10/08/07; accepted 01/08/08. Author for correspondence: Chung-Chih Liu (e-mail: ccliu@must.edu.tw).

* Teaching Center of Natural Science, Minghsin University of Science and Technology, Hsin-Chu county, Taiwan, R.O.C.

** Department of Geography, Chinese Culture University, Taipei, Taiwan, R.O.C.

*** Weather Wing of Air Force, Taipei, Taiwan, R.O.C.

\section{INTRODUCTION}

Typhoons are one of nature's most destructive weather systems. Most of them form and develop over the ocean. However, traditional observations are often not sufficient, due to the difficulty and resources required for the data collection. Thus, satellite remote sensing data serves as a much better choice in terms of its spatial and temporal resolutions. The geostationary meteorological satellite has become an available tool for determining the typhoon location, structure and intensity. When geostationary satellite images were available, the identification and tracking of tropical cyclones turned into a trivial task. However, many problems still exist in terms of weaker tropical cyclones. The scientists at NOAA/NESDIS led by Vern Dvorak developed satellite applications specifically aimed toward the operational forecasting of tropical cyclones. They proposed a methodology for determining the intensity of tropical cyclone based on subjective cloud pattern recognition in 1975 [6]. That procedure came to be known as the Dvorak technique. Later, it was supplemented with the enhanced infrared method in 1984 [7]. Such techniques were based on empirical rules in determining the intensity of tropical cyclones in "T numbers". A T-number unit represents a typical one-day intensity change. The Dvorak technique gives intensities in terms of $0.5 \mathrm{~T}$-number increments by using a table, which converts the T-number into surface wind speed. Moreover, a pressure-wind relationship was also used to assign minimum sea-level pressure. However, the downside of the Dvorak algorithm is that the "T number" is determined subjectively. Velden introduced an objective Dvorak technique (ODT) to largely eliminate the subjective manual process in the original Dvorak method [10, 13]. The satellite wind fields from the scatterometers over the ocean were used frequently by some typhoon researchers. The backscatter depends not only on the magnitude of the wind speed, but also on the wind direction in regards to the direction of the radar beam $[2,8]$. Some spaced-based scatterometers operating on polar-orbiting satellites provide both wind speed and direction. The empirical form of the original scatterometer algorithm leads to an asymptotic decrease in the sensitivity in scatterometer-derived winds for higher wind speeds [5]. Some improvement of wind retrieval algorithms over the ocean under the 
(a)
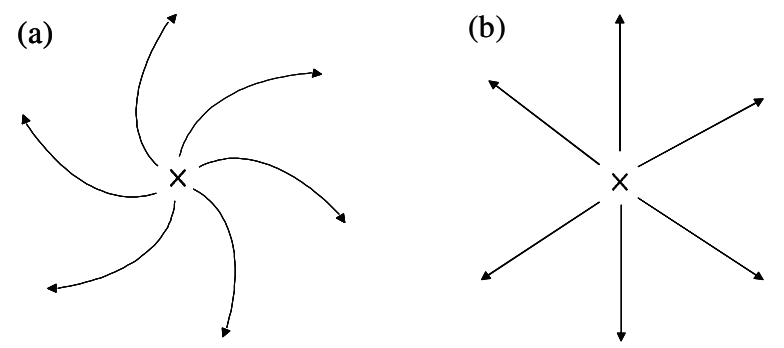

Fig. 1. The conceptual airflow pattern of a high level typhoon (a) anticyclone pattern, (b) an outward radiating flow.

higher wind speed conditions of tropical cyclones were thus also proposed [19].

The structures of tropical cyclones have been extensively studied in the last three decades by using data from research aircraft, rawinsonde composites, satellite analysis and numerical model simulations. The tropical cyclone structure covers many scales, including the size of the low-level cyclonic circulation, the radius of the maximum sustained wind speed, the symmetric and asymmetric structures of the eyewall, and the inner and outer spiral rainbands [16]. A typical typhoon structure with a warm core vortical circulation, cyclonic (counter-clockwise circulation) in the lower and anticyclonic (clock-wise circulation) in the upper troposphere, with the strongest winds and torrential rains in the eyewall cloud, with downward motion and calm winds in the area of typhoon eye were considered to be real. In addition, the concept of elevated cyclonic potential vorticity concentrated in the inner core region near the radius of the maximum sustained wind with large radial gradients was accepted. The potential vorticity waves may play an important role in tropical cyclone structure and intensity changes $[9,11,14,15]$. Although there exist multi-scale interactions related to tropical cyclone development, motion, and changes of structure and intensity, the forecast of tropical cyclone motion has improved, due to advanced observations, especially in the satellite [12] and dropwindsonde [1, 4, 18] data. However, the tropical cyclone structure and intensity are easily affected by complex physical processes $[2,17]$. Therefore, the understanding and forecasting of tropical cyclone structure and intensity changes are still difficult. This research does not aim to develop a method for determining or forecasting the typhoon intensity. Instead, this study strives to analyze the special phenomenon of the high-level cirrus changes during the typhoon development process. Within a typical typhoon structure, the low level air moves to the inner core, lifts up and moves outwards at the higher level. Moreover, the high level air flow of typhoon moves anticyclonically (shown as Fig.1(a)). However, the high level airflow of Typhoon Longwang radiated from the center during a certain time period (Fig. 1(b)). One may ask whether it would be possible to determine the typhoon intensity by analyzing and recognizing the cloud pattern through satellite images? Consequently, the goal of this research is to examine the relation between Typhoon Longwang's intensity and the characteristics observed by satellite images.

The paper is structured as follows. Data collection and processing are shown in Section II. Afterwards, the methodology is described in Section III. The analysis and discussion are shown in Section IV. Finally, a conclusion is given in Section V.

\section{DATA}

GOES9 is a geostationary meteorological satellite. It provides hourly observations of visible data, as well as two infrareds observations (over channels IR1, 10.5 11.5 $\mu \mathrm{m}$ and IR2, 11.5 12.5 $\mu \mathrm{m}$ ), and water vapor observations (over channels $\mathrm{WV}, 6.5 \sim 7.0 \mu \mathrm{m})$. The resolutions of the visible and infrared channels are $1.25 \mathrm{~km}$ and $5 \mathrm{~km}$, respectively. In this study, the data from the IR1 channel was employed. The brightness temperature data of original IR1 channel was resampled into $0.05^{\circ}$ by $0.05^{\circ}$ longitude-latitude grid for calculation.

The best track typhoon data from Joint Typhoon Warning Center (JTWC) was used to identify the change in intensity, radius of the $17.2 \mathrm{~m} / \mathrm{s}$ wind structure, and the overall typhoon movement. In terms of the analysis of the synoptic environment field, a $1.125^{\circ}$ by $1.125^{\circ}$ grid point of every six hours from the global model data of the Tropical Ocean Global Atmosphere Advanced format data of the European Centre for Medium-Range Weather Forecasts (ECMWF) was used. This included 6 weather factors: geopotential height, temperature, horizontal wind field ( $\mathrm{u}$ and $\mathrm{v}$ components), vertical velocity, and relative humidity.

\section{METHODOLOGY}

The high level cirrus system of Typhoon Longwang was observed as an outward flow in a non-rotation motion during 0000UTC to 1200UTC 30 September, 2005. In order to prove the observed phenomenon, a statistical method was used for analyzing. First we set the center of the typhoon as the reference point $\mathrm{P}\left(\mathrm{x}_{0}, \mathrm{y}_{0}\right)$ which was a geometric origin of the polar coordinates. The typhoon was subsequently equally divided into 16 parts $(n=1,2, \ldots, 16)$ as shown in Fig. 2. The mean distance $x_{i}$ $(\mathrm{i}=1,2,3, \ldots, 16)$ is the length from the center to the grid point with a specific brightness temperature. The value depends on the outward extension of the typhoon's high-level cirrus system. A longer mean distance represents the farther out outer high level cirrus system of the typhoon, and a smaller value represents the nearer high level cirrus system to the center of the typhoon. This stems from the fact that the high brightness temperature values (greater than $250 \mathrm{~K}$ ) around the typhoon system always cover the areas beyond the principle circulation of the typhoon. In addition, the low brightness temperature value (smaller than $220 \mathrm{~K}$ ) always cover the stronger convective cloud system near the center of the typhoon. Therefore, the specific brightness temperature values were set as $220 \mathrm{~K}, 230 \mathrm{~K}$, $240 \mathrm{~K}$ and $250 \mathrm{~K}$ in this study. By averaging the distance from the center of typhoon to the point with a specific brightness temperature value in 16 fan-shaped areas, a mean value could be obtained as follows. 


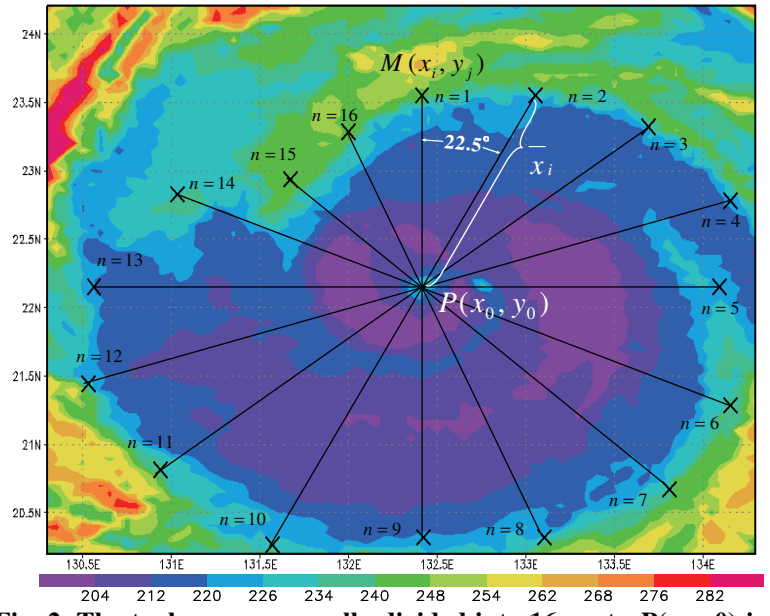

Fig. 2. The typhoon was equally divided into 16 parts. $P(x 0, y 0)$ is the centre of the typhoon, $\mathrm{M}(\mathrm{xi}, \mathrm{yi})$ is the location of the brightness temperature value (in this study it was set as 220 $\mathrm{K}, 230 \mathrm{~K}, 240 \mathrm{~K}$, and $250 \mathrm{~K}$ ), and $\bar{x}$ is the mean distance between the 16 portions. The color bar represents the brightness temperature $(\mathbf{K})$.

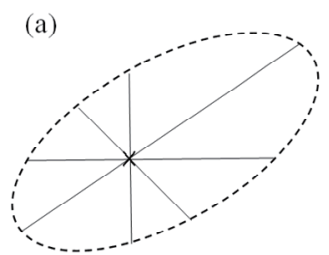

(b)

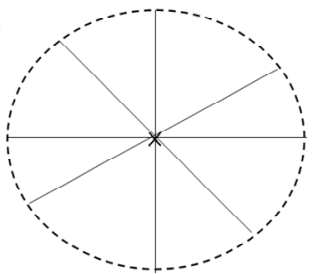

Fig. 3. The different typhoon cloud distributions. (a) A greater $S$ value represents asymmetric distribution and (b) A smaller $S$ value represents symmetric distribution.

$$
\bar{X}=\frac{\sum_{i=1}^{16} x_{i}}{16}
$$

The standard deviation of the distance is calculated as follows.

$$
S=\sqrt{\frac{1}{n-1} \sum_{i=1}^{n}\left(x_{i}-\bar{X}\right)^{2}}
$$

A higher $S$ value implies that the cloud is distributed in a more irregular way (does not resemble like a disk). The $\mathrm{S}$ smaller value implies that it is distributed as a disk (shown in Fig. 3).

\section{ANALYSIS AND DISCUSSION}

Typhoon Longwang formed over the ocean at longitude $144^{\circ}$ E and latitude $20^{\circ} \mathrm{N}$ at 2200UTC 25 September, 2005 (as shown in Fig. 4). The intensity of Typhoon Longwang continued to increase after its formation. Although becoming a strong typhoon at 1800UTC 27 September, its intensity kept increasing. Its only began to weaken at 0600UTC 30 September. From the

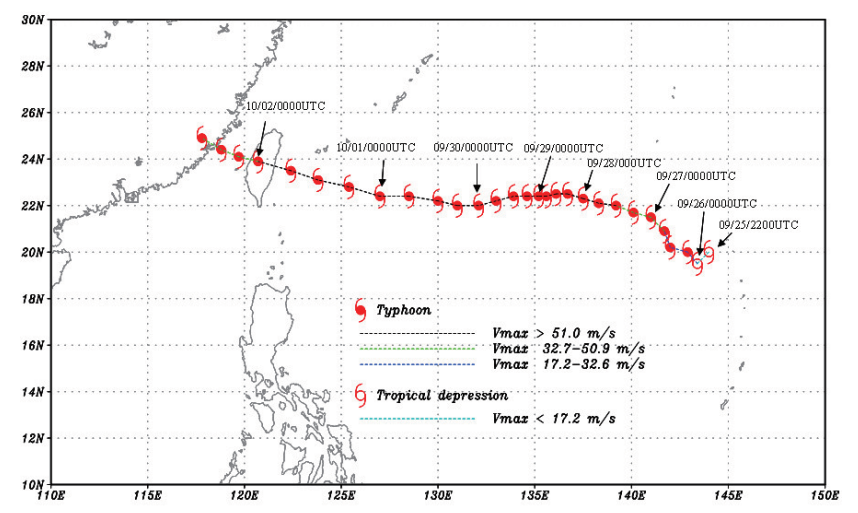

Fig. 4. The best track of Typhoon Longwang during 25 September to 02 October, 2005.

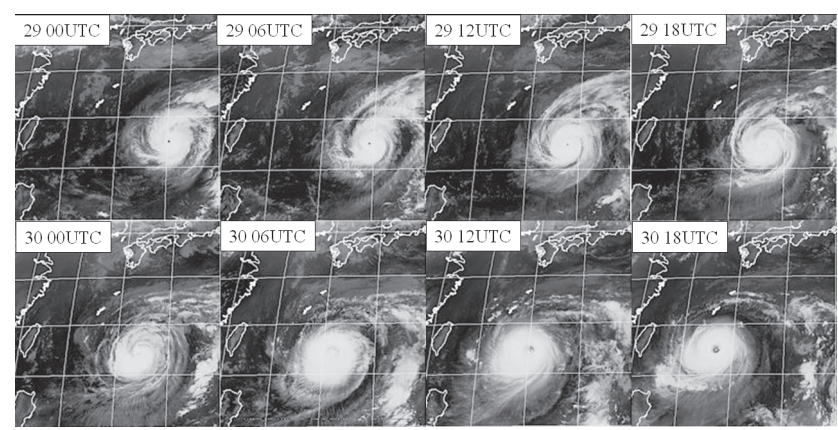

Fig. 5. The infrared cloud images (very 6 hours) from 0000UTC 29 September to 1800UTC 30 September, 2005.

infrared images of GOES9 (shown as Fig. 5), the distribution of the spiral cloud bend was very obvious from 0000UTC 29 to 0000UTC 30 September. At the same time, the flow of the high level cirrus moved outward and anticyclonically. However, since 0600UTC 30 September, the spiral cloud bend became less obvious, and the high level cirrus began to radiate from the center of Typhoon Longwang based on the satellite image animations (Fig. 6). It seemed there was an obvious change in the structure of the typhoon during 0000UTC to 0600UTC 30 September. The spiral cloud bend is obvious at 0000UTC 30 September, and its distribution was asymmetrical. However, it was clearly seen that the spiral cloud bend came to a different form from 0600UTC 30 September. Furthermore, the pattern of the cloud system became more symmetrical (like a disk). The cloud system of the typhoon maintained a symmetrical development during 0600UTC to 1800UTC 30 September. Afterwards, the eye of the typhoon (area in the center with greater brightness temperature value) became larger and clearer.

In addition to a qualitative analysis, a quantitative analysis was made on the typhoon high-level cirrus system during 0000UTC to 1200UTC 30 September. The center of the typhoon was set as the reference point. The mean and the standard deviation of the distance from the center to the location with a specific brightness temperature value were calculated (shown in the previous section). Fig. 7a shows the mean value changes over time for different specific brightness temperature values $(220 \mathrm{~K}, 230 \mathrm{~K}, 240 \mathrm{~K}, 250 \mathrm{~K})$. During the period from 


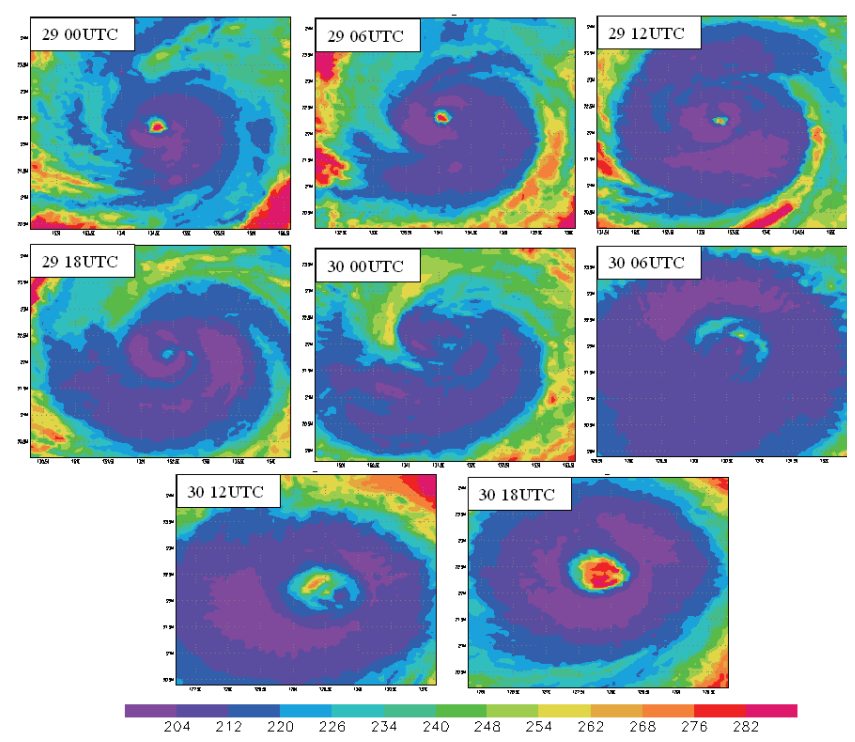

Fig. 6. The brightness temperature images of Typhoon Longwang from 0000UTC 29 September to 1800UTC 30 September, 2005.

0600UTC to 1800UTC 29 September, the mean distance kept increasing, an indication that the area of the typhoon high-level cirrus was increasing. However, at 0000UTC 30 September, the mean value decreased obviously. It increased again at 0600UTC 30 September. The decrease at 0000UTC 30 September was actually caused by clouds with larger brightness temperature values near the center of the typhoon (as shown in Fig. 6). The standard deviation change over time is shown in Fig. 7(b)---all the standard deviation calculated are greater than 50 kilometer during 0000UTC to 0600UTC 29 September. Although it decreased obviously at 1200UTC, both the standard deviation and the mean value increased rapidly after that time. This showed that the high-level cirrus cloud system tend to distribute in a symmetrical pattern at 1200UTC 29 September (Fig. 6). Although the cloud system did not maintain a symmetrical distribution during 1800UTC 29 to 0000UTC 30 September, it changed to a symmetrical pattern after 0000UTC 30 September. It is interesting to see that all the standard deviations were small after 0000UTC 30 September, an implication that the distribution of the cloud system was symmetric. The mean distance value for varied brightness temperature values increased obviously, while the standard deviation decreased rapidly during 0000UTC to 0600UTC 30 September, signifying that the high level cirrus cloud system of the typhoon flowed outward in a nearly disk shape.

From the results seen above, the structure of Typhoon Longwang appeared to be in a transition state (from asymmetrical to symmetric distribution) from 0000UTC to 0600UTC 30 September. The change in the intensity, radius of the $17.2 \mathrm{~m} / \mathrm{s}$ wind speed, and movement of the typhoon during that period were worth paying attention to. The JTWC best track showed that Typhoon Longwang's intensity during the period from 1200UTC 29 to 0000UTC 30 September (as shown in Fig. 8(a)). Moreover, the intensity of the typhoon decreased obviously
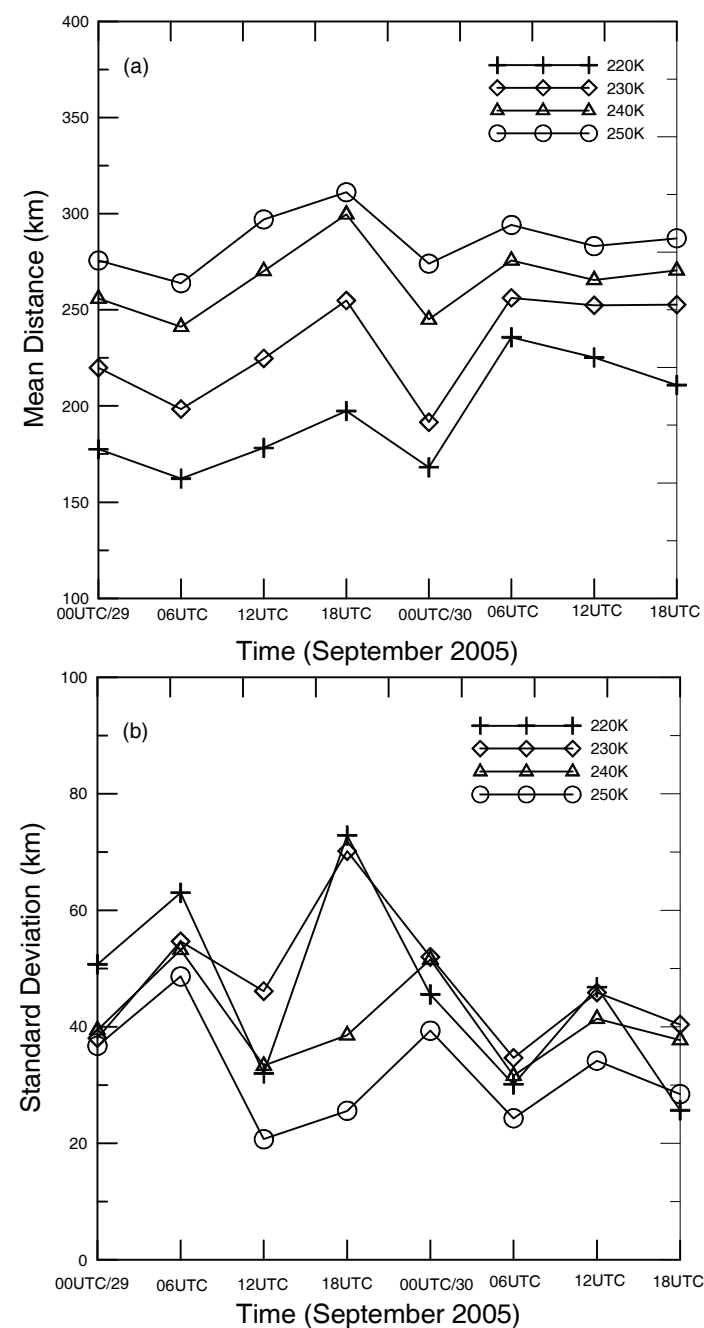

Fig. 7. (a) The time serial of mean distance value for different specific brightness temperature values $(220 \mathrm{~K}, 230 \mathrm{~K}, 240 \mathrm{~K}$, $250 \mathrm{~K})$. (b) the same as (a) but in terms of the standard deviation.

from 0000UTC to 0600UTC 30 September. However, JTWC's larger $17.2 \mathrm{~m} / \mathrm{s}$ radius size of Typhoon Longwang during that period may be attributed partly to the manmade decision in using satellite infrared images. The speed of the typhoon almost remained unchanged during 1800UTC 29 September to 1200UTC 30 September (shown as Fig. 8(b)). It was only until 1800 UTC did the speed began to increase apparently.

According to the aforementioned discussions, the high-level cirrus system of Typhoon Longwang did radiate and enlarge in a disk-like shape during 0000UTC to 0600UTC 30 September. The relation between the mean vertical distribution of environmental divergence and vorticity and the intensity of typhoon were examined through the objective analysis of ECMWF (shown as Fig. 9). The height-time vertical profile of divergence and vorticity were calculated for the typhoon area $\left(0.05^{\circ}\right.$ by $0.05^{\circ}$ longitude-latitude grid from typhoon center). The maximum divergence value was at the height of $200 \mathrm{hPa}$ at $0000 \mathrm{UTC}$ 30. Later, the high level divergence weakened, yet, a stronger convergence changed to a weaker divergence from 0000UTC to 

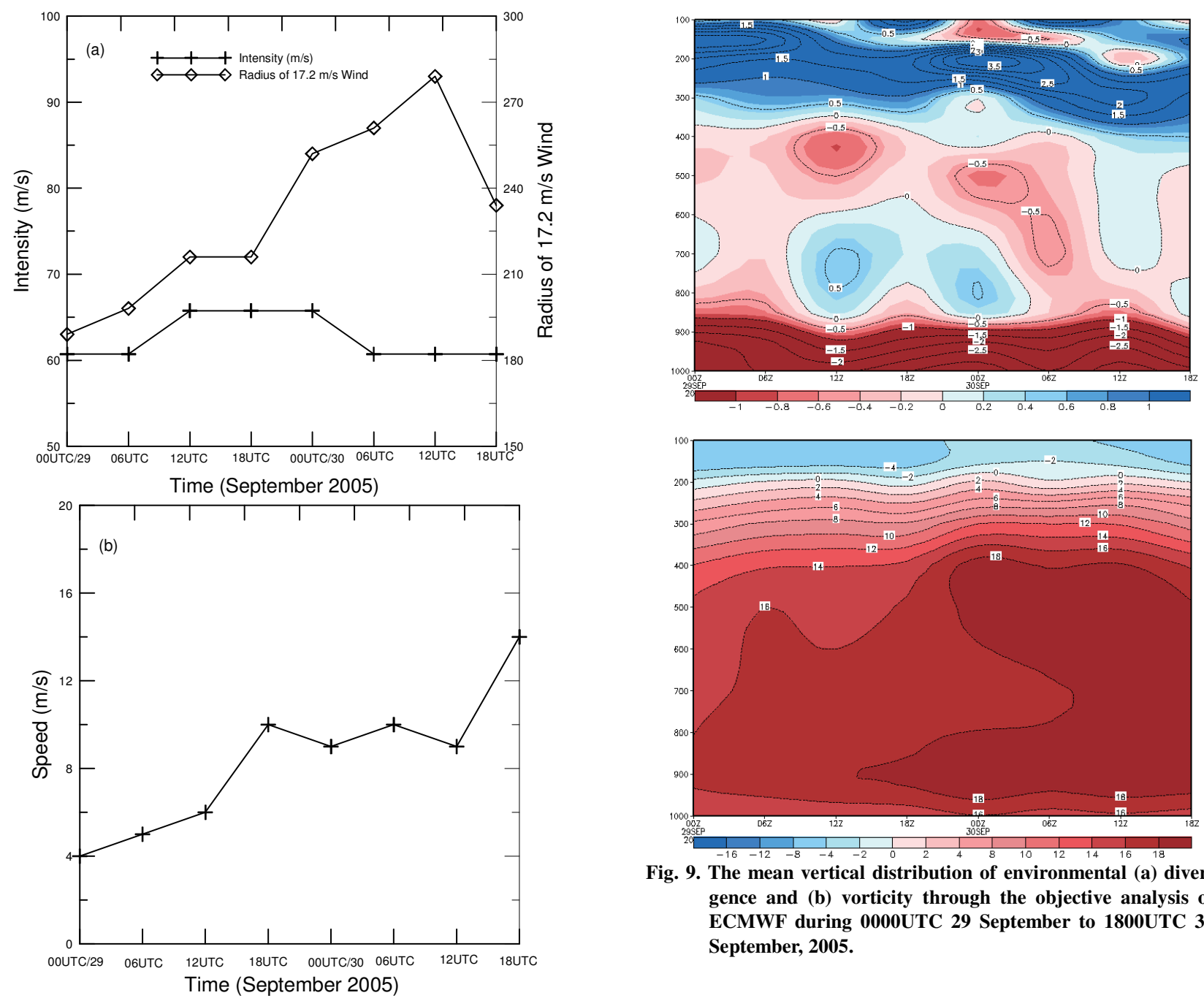

Fig. 9. The mean vertical distribution of environmental (a) divergence and (b) vorticity through the objective analysis of ECMWF during 0000UTC 29 September to 1800UTC 30 September, 2005.

Fig. 8. The (a) intensity, radius of $17 \mathrm{~m} / \mathrm{s}$ wind and (b) speed of Typhoon Longwang during 0000UTC 29 September to 1800UTC 30 September, 2005.

1200UTC 30 September at the middle 700-400 $\mathrm{hPa}$ pressure level. The stronger convergence flow below $850 \mathrm{hPa}$ did not change very much (shown as Fig. 9(a)). The change of the middle level vorticity was small from 0000UTC to 1200UTC 30 September. However, the negative vorticity value at 100-200 $\mathrm{hPa}$ of the high level decreased obviously during that period (shown as Fig. 9(b)). From the divergence and the vorticity field data, the outflow and rotation at the high level decreased synchronically from 0000UTC to 1200UTC 30 September. It should be noted that Typhoon Longwang's intensity decreased during that period. Moreover, the mean distance from the typhoon center to a specific brightness temperature value increased gradually from 0000UTC 30 September, but the standard deviation of the distance was small. Also, the high level cirrus of Typhoon Longwang expanded outwards in a disk-like shape, and the rotation of an anticyclone decreased obviously.

The outflow of a typhoon's high-level cloud system will naturally induce an anticyclone flow, due to the coriolis effect. The radiating flow in this case is merely a temporary phe-

nomenon, which may be attributed to a complex mesoscale process. According to the operational center's past observations, a, typhoon's intensity decreases frequently during such short time periods, which is thus a point worthy of pointing out.

\section{CONCLUSIONS}

In this study, it was found that the high-level cirrus system of Typhoon Longwang radiated from the center during 0000UTC to 0600UTC 30 September. It is interesting to observe how the operational center determined the change of the typhoon intensity. Results show that the structure of Typhoon Longwang did change during 0000UTC to 1200UTC 30 September, whether from a qualitative (cloud images and distribution of brightness temperature) or a quantitative standpoint (mean and standard deviation of distance of brightness temperature). In addition, the high- level cirrus system of the typhoon was also seen to radiate from the typhoon center. What does this all imply? From the best track data of JTWC, the intensity of Typhoon Longwang decreased evidently during that period, while the wind speeds almost stayed unchanged. Only the radius of $17.2 \mathrm{~m} / \mathrm{s}$ wind continued to increase. However, at 1800UTC 30 September, the 
radius of Typhoon Longwang decreased suddenly, implying that the radius of Typhoon Longwang perhaps should be smaller than that from JTWC during the 0000UTC to 1800UTC 30 September.

On the other hand, by analyzing the vertical distributions of the divergence and vorticity from ECMWF, the divergence and rotation at the higher levels both decreased during that time. That may be the reason why Typhoon Longwang's intensity decreased during that period, which can also explain the phenomenon that was observed from the satellite images---high-level cirrus clouds of Typhoon Longwang switching from an anticyclone and outward pattern into a disk-shape and radiating orientation.

Although only the simple mechanical processes were discussed in this study, a reasonable result was obtained. As only a single case was examined in this study, it is suggested that additional case studies should be conducted in the future.

\section{ACKNOWLEDGMENTS}

This research is primarily supported by The National Science Council, R.O.C. with grants 96-2625-Z-159-002 and 96-2745M-159-001. Meanwhile, we also would like to thank the Weather Central CAFROC for providing the satellite data.

\section{REFERENCES}

1. Aberson, S. D. and Franklin, J. L., "Impact on hurricane track and intensity forecasts of GPS dropwindsonde observations from the first-season flights of the NOAA gulfstream-IV jet aircraft," Bulletin of the American Meteorological Society, Vol. 80, pp. 421-427 (1999).

2. Attema, E. P. W., "The active microwave instrument on board the ERS-1 satellite," Proceedings of the IEEE Publication, Vol. 79, pp. 791-799 (1991).

3. Bosart, L. F., Velden, C. S., Bracken, W. E., Molinari, J., and Black, P., "Environmental influence on the rapid intensification stage of hurricane Opal (1995) over the Gulf of Mexico," Monthly Weather Review, Vol. 128, pp. 322-352 (2000).

4. Burpee, R. W., Franklin, J. L., Lord, S. J., Tuleya, R. E., and Aberson, S. D., "The impact of Omega dropwindsondes on operational hurricane track forecast models," Bulletin of the American Meteorological Society, Vol. 77, pp. 925-933 (1996).

5. Cavanie, A. and Lecomte, P., "Study of a method to deal with winds from ERS-1data," European Space Agency Final report, Contract \#6874-87GP-1 (1987).
6. Dvorak, V. F., "Tropical cyclone intensity analysis and forecasting from satellite imagery," Monthly Weather Review, Vol. 103, pp. 420-430 (1975).

7. Dvorak, V. F., "Tropical cyclone intensity analysis using satellite data," NOAA Technical Report NESDIS, 11, pp. 47 ( 1984).

8. Jones, C., Peterson, P. and Gauiter, C., "A new method for deriving ocean surface specific humidity and air temperature: an artificial the cloud neural network approach," Journal of Applied Meteoroloy., Vol. 38, pp. 1229-1246 (1999).

9. Montgomery, M. T. and Kallenbach, R. J., "A theory for vortex Rossby-waves and its application to spiral bands and intensity changes in hurricanes," Quarterly Journal of the Royal Meteorological Society, Vol. 123, pp. 435-465 (1997).

10. Olander, T. L., and Velden, C. S., "UW-CIMSS objective Dvorak technique (ODT) ," Preprints, 23d Conference on Hurricanes and Tropical Meteorology, Dallas, Texas, American Meteorological Society, pp. 435-436 (1999).

11. Schubert, W. H., Montgomery, M. T., Taft, R. K., Guinn, T. A., Fulton, S. R., Kossin, J. P., and Edwards, J. P., "Polygonal eyewalls, asymmetric eye contraction, and potential vorticity mixing in hurricanes," Journal of the Atmospheric Sciences, Vol. 56, pp. 1197-1223 (1999).

12. Soden, B. J., Velden, C. S., and Tuleya, R. E., "The impact of satellite winds on experimental GFDL hurricane model forecasts," Monthly Weather Review. Vol. 129, pp. 835-852 (2001).

13. Velden, C. S., Olander, T. L., and Zehr, R. M., "Development of an objective scheme to estimate tropical cyclone intensity from digital geostationary satellite infrared imagery," Weather and Forecasting, Vol. 13, pp. 172-186 (1998).

14. Wang, Y., "Vortex Rossby waves in a numerically simulated tropical cyclone. Part I: overall structure, potential vorticity and kinetic energy budgets," Journal of the Atmospheric Sciences, Vol. 59, pp. 1213-1238 (2002).

15. Wang, Y., "Vortex Rossby waves in a numerically simulated tropical cyclone. Part II: the role in tropical cyclone structure and intensity change," Journal of the Atmospheric Sciences, Vol. 59, pp. 1239-1262 (2002).

16. Wang, Y., and Wu, C. C., "Current understanding of tropical cyclone structure and intensity changes - a review," Meteorology and Atmospheric Physics, Vol. 87, pp. 257-278 (2004).

17. Wu, C. C. and Cheng, H. J., "An observational study of environmental influences on the intensity changes of typhoons Flo (1990) and Gene (1990) ," Monthly Weather Review, Vol. 127, pp. 3003-3031 (1999).

18. Wu, C. C., Lin, P. H., Sim, A., Yeh, T. C., Huang, W. P., Chou, K. H., Hong, J. S., Lu, G. C., Fong, C. T., Hsu, K. C., Lin, I. I., Lin, P. L., and Liu, C. H., "Dropwindsonde observations for Typhoon Surveillance near the Taiwan region (DOTSTAR): an overview," Bulletin of the American Meteorological Society, Vol. 86, No. 6, pp. 787-790 (2005).

19. Yueh, S. H., West, R., Li, F., Tsai, W. Y., and Lay, R., "Dual-polarized $\mathrm{Ku}$-band backscatter signatures of hurricane ocean winds," IEEE, Transactions on Geoscience and Remote Sensing, Vol. 38, pp. 73-88 (2000). 